DOI 10.37882/2223-2982.2020.07.18

\title{
ОСОБЕННОСТИ СЛОВООБРАЗОВАНИЯ И ФУНКЦИОНИРОВАНИЯ ЛЕКСИЧЕСКИХ ЕДИНИЦ, УПОТРЕБЛЯЮЩИХСЯ В РОЛИ «ПРИЛАГАТЕЛЬНОГО» В ТУНДРЕННОМ ДИАЛЕКТЕ ЮКАГИРСКОГО ЯЗЫКА
}

\section{FEATURES OF WORD-FORMATION AND FUNCTIONING OF LEXICAL UNITS USED IN THE ROLE OF "ADJECTIVE" IN THE TUNDRA DIALECT OF YUKAGIR LANGUAGE}

\section{Lukina}

Summary: This article reveals the features of word formation and the functioning of lexical units used as an "adjective" in the tundra dialect of the Yukagir language. As a result of the study, "doubleness" of the content and functioning of the indicated lexical units is revealed, which is expressed in the manifestation of some lexical units that are used as "adjective" as verbal words, and others as nominal, bearing nominal characters. This feature of word formation and the functioning of lexical units used as an "adjective" indicates the difficulty of distinguishing this group of words as a separate part of speech in the tundra dialect of the Yukagir language.

Keywords: Yukagir language, tundra dialect, participles, quality verbs.
Лукина Маргарита Петровна

к.филол.н., н.с., Институт гуманитарных исследований и проблем малочисленных народов Севера Сибирского отделения Российской академии наук, г. Якутск margarita-lukina@yandex.ru

Аннотация: В статье раскрываются особенности словообразования и функционирования лексических единиц, употребляющихся в роли «прилагательного» В тундренном диалекте юкагирского языка. В результате исследования выявляется «двоякость» содержания и функционирования указанных лексических единиц, что выражается в проявлении некоторых лексических единиц, употребляющихся в роли «прилагательного» как глагольных слов, а других, - как именных, несущих в себе именные признаки. Такая особенность словообразования и функционирования лексических единиц, употребляющихся в роли «прилагательного», свидетельствует о трудности выделения данной группы слов в отдельную часть речи в тундренном диалекте юкагирского языка.

Ключевые слова: юкагирский язык, тундренный диалект, причастия, качественные глаголы.

\section{Введение}

B опрос разграничения частей речи является центральным в грамматике любого языка, однако многие вопросы грамматики юкагирского языка все еще остаются малоисследованными. Особую трудность при разграничении частей речи в юкагирском языке вызывают лексические единицы со значением «количества» и лексические единицы, употребляющиеся в роли «прилагательного». Так, исследователи юкагирского языка отмечали, что слова с качественными и количественными значениями, т.е. «прилагательные» и «числительные» в юкагирском языке ведут себя как глагольные слова. По этому поводу В.И. Иохельсон писал, что «имя прилагательное» в юкагирском языке особой формы не имеет, а «количественные числительные» изменяются как глаголы, а не как имена существительные [1, с.165]. Е.А. Крейнович также считал, что «прилагательных» в юкагирском языке нет. Их значения выражаются при помощи качественных глаголов; не обособлял в отдельную часть речи и числительные [3]. Однако, Г.Н. Курилов в своей работе «Современный юкагирский язык», лекси- ческие единицы со значением «количества» выделил в качестве самостоятельной части речи под общепринятым названием «числительное», а лексические единицы, употребляющиеся в роли «прилагательного», - в самостоятельную часть речи под названием «квалитатив». При этом он подчеркнул, что количественные числительные первого десятка в юкагирском языке, действительно являются глагольными словами, а «квалитативы» подразделил на именного и глагольного типов [7, с. 109, 133].

Итак, в трудах исследователей по юкагирскому языку мы не находим единого мнения по поводу разграничения частей речи в грамматике юкагирского языка.

Актуальность исследования особенностей словообразования и функционирования лексических единиц, употребляющихся в роли «прилагательного» в тундренном диалекте юкагирского языка, определяется, прежде всего, следующими обстоятельствами:

1. трудностью разграничения частей речи в юкагирском языке; 
2. неоднородностью подходов исследователей по юкагирскому языку для разграничения частей речи, в частности, выделения слов с качественными значениями, т.е. «прилагательных» в отдельную часть речи.

Целью исследования является выявление и системный анализ особенностей словообразования и функционирования лексических единиц, употребляющихся в роли «прилагательного» в тундренном диалекте юкагирского языка для определения их статуса.

Научная значимость исследования состоит в раскрытии особенностей словообразования и функционирования лексических единиц, употребляющихся в роли «прилагательного» в тундренном диалекте юкагирского языка, тем самым раскрываются некоторые особенности грамматики юкагирского языка. В результате анализа словообразования и функционирования лексических единиц, употребляющихся в роли «прилагательного» в тундренном диалекте юкагирского языка, выявлена «двоякость» содержания и функционирования указанных лексических единиц, что выражается в проявлении некоторых лексических единиц, употребляющихся в роли «прилагательного» как глагольных слов, а других, - как именных.

Материалом исследования по тундренному диалекту послужили данные юкагирско-русского словаря [5], а также материалы автора, собранные по время фольклорно-лингвистических экспедиций в места компактного проживания тундренных юкагиров (2001 - 2015).

По территориальным и языковым признакам принято различать тундренный и колымский диалекты юкагирского языка. Исследования последней четверти XX века показали, что эти диалекты приобрели структурносемантические черты самостоятельных языков. Значительные расхождения между диалектами имеется, особенно, в сфере лексики, что позволяет рассматривать их как два близкородственных языка.

Юкагирский язык по сей день остается значительно слабее обследованным по сравнению с другими языками. Так, в грамматике юкагирского языка не решены вопросы категории времени, взаимодействие центральных категорий глагола: наклонений, переходности/непереходности, времени, актуального членения предложений, модальности, залога, вида и т.д.

Е.А. Крейнович отмечал своеобразие слов юкагирского языка и трудность их деления на части речи, а также своеобразие структуры языка, подчиненную логическому ударению $[2,3]$. В первых своих работах им выделены следующие части речи: имя существительное, имя действия, местоимение, глагол, наречие, послелоги и междометия [2].

В юкагирском языке ряд количественных слов стал вести себя подобно глаголам, частично изменяясь по лицам, числам, времени. Такое необычное поведение качественных и количественных слов подтолкнуло Е.А. Крейновича [2] признать их глагольными словами. Так, Е.А. Крейнович определял их как особые семантические разряды глагола и в последней своей работе он включил их в группу «процессивов»: слова с качественными и количественными значениями - «качественный процессив» и «количественный процессив» [4]. Е.А. Крейнович отмечает, что в юкагирском языке формы процессива передают процессуальные, качественные и количественные признаки. Процессив по Е.А. Крейновичу имеет грамматические категории непереходности - переходности, способы действия, залога, наклонения, времени, лица и числа. Процессивные формы делятся на предикативные, зависящие от падающего на них логического ударения, деепричастные и определительные [4].

Г.Н. Курилов, в свою очередь, выделяет следующие знаменательные части речи в юкагирском языке: имя существительное, имя действия, числительное, местоимение, квалитатив, глагол, наречие, а также служебные слова: служебные глаголы, частицы, союзы, послелоги, модальные слова, междометия [7, 279].

Формирование лексического состава юкагирского языка является длительным и сложным процессом. Впервые образцы аффиксального образования именных и глагольных слов в юкагирском языке приводил в своих работах Е.А. Крейнович [2, 3, 4]. Однако, более детально проблема аффиксального словообразования в юкагирском языке, была рассмотрена Г.Н. Куриловым [6,7].

Глагол в юкагирском языке является главной частью речи и во всех отношениях самой сложной. Г.Н. Курилов полагает, что на раннем этапе развития языка глагол, как обозначение действия и процесса, играл в речи большую роль, чем имя существительное. Косвенным доказательством этого может служить тот факт, что глагол смог «перетянуть» на свою сторону слова с качественными значениями, которые обычно функционируют в составе именных слов. Правда, в этой «победе» глагола над «именами» решающую роль сыграли, во-первых, система актуального членения предложения в юкагирском языке, во-вторых, семантическая родственность слов с качественными значениями и глаголов как обозначений признаков предметов. Эта родственность именных частей речи по общекатегориальному значению с глаголами чуть было не оглаголила и числительные [7].

Итак, глагол в юкагирском языке представляет собой очень своеобразную часть речи. Исследователи юкагирского языка к глаголу относят не только обозначения 
действия и состояний, но и обозначения качественных и количественных признаков, таким образом, к классу глаголов в юкагирском языке относят:

1. собственно глаголы, т.е. формы глаголов, обозначающие действие и процесс;

2. качественные глаголы;

3. количественные глаголы;

4. причастия;

5. деепричастия;

6. имя признака.

Глаголы, в свою очередь, подразделяются на непереходные и переходные. Первые подразделяются еще на три лексико-семантические группы:

1. собственно- непереходные глаголы (кэвэч «ушел (он)», мони «сказал(он)»);

2. качественные глаголы (вэрвэй «сильный есть», амуч «хороший (он есть)», чамуонь «большой (он есть)» ;

3. количественные глаголы (моорхуонь «один (он есть)»).

В целом, лексические единицы, употребляющиеся в роли «прилагательного» в юкагирском языке можно подразделить на 2 группы:

1. лексические единицы глагольного типа, употребляющиеся в роли «прилагательного»;

2. лексические единицы, употребляющиеся в роли «прилагательного» именного типа.

В свою очередь 1 группа лексических единиц глагольного типа, употребляющиеся в роли «прилагательного» подразделяются на 2 формы:

1. глаголы-лексические единицы, употребляющиеся в роли «прилагательного»;

2. атрибутивная форма лексических единиц, употребляющихся в роли «прилагательного».

\section{Глаголы-лексические еАинишы, употребляюшиеся в роли «прилагательного»}

Глаголы-лексические единицы, употребляющиеся в роли «прилагательного» действительно ведут себя как непереходные глаголы.

Прежде чем рассмотреть особенности словообразования и функционирования лексических единиц, употребляющихся в роли «прилагательного» в тундренном диалекте юкагирского языка, следует рассмотреть особенность грамматики юкагирского языка, которая ориентирована на выражение коммуникативной структуры предложения: закономерности употребления всех основных категорий глагола и имени подчиняются задачам актуального членения на тему и рему с точки зрения существенности передаваемой информации, что отражается в трех формах глагола, а именно, - субъектного, предикативного и объектного. Актуальное членение предложения, точнее, выделение важных частей высказывания, в юкагирском языке реализуется грамматическими показателями субъекта и показателями, имеющими свойства предиката, иными словами, сообщение о новом осуществлено посредством различного грамматического оформления главных членов предложения.

\section{Ремо-субъектная форма глагола}

Со стороны содержания ремо-субъектная форма глагола характеризуется тем, что логическое ударение сосредотачивается на субъекте действия. С формальной стороны это выражается в том, что глагол не принимает префикса - мэ(р) и личных окончаний. Вместо последних основа глагола оформляется суффиксом - л. Субъект же принимает форму на -эк.

\section{Непереходный глагол в ремо-субъектной форме}

Мэтэк хусэйл «Я прыгал»

Тэтэк хусэйл «Ты прыгал»

Тудэл хусэйл «Он прыгал»

Митэк хусэйл «Мы прыгали»

Титэк хусэйл «Вы прыгали»

Титтэк хусэйл «Они прыгали».

Глаголы-лексические единишы на -^, употребляюшиеся в роли «прилагательного» в ремо-субъектной форме

Глаголы-лексические единицы, употребляющиеся в роли «прилагательного» в ремо-субъектной форме, отвечают на вопрос типа: Кинэк амуол? «Кто хороший?». При этом раскрывают признак, выраженный глаголом - сказуемым, но носитель признака неизвестен. В связи с этим в предложении, служащим ответом на вопрос, логическое ударение сосредотачивается на подлежащем, которым в данном случае раскрывается носитель признака. Подлежащее оформляется показателем -эк, а в роли сказуемого выступает лексическая единица, употребляющаяся в роли «прилагательного», не выражающая логического ударения:

Митэк амуол «Мы хорошие», Титэк амуол «Вы хорошие» и т.д.

Лексические единицы на -л, употребляющиеся в роли «прилагательного» в ремо-субъектной форме ведут себя как непереходные глаголы в этой форме.

Предметный непереходный глагол. От основы каждого имени существительного посредством вспомогательного глагола -но, означающего «быть» образована основа предметного непереходного глагола со значением «быть тем, что указано основой имени существительного, от которой образован данный глагол». Предметным непе- 
реходным глаголом выражается представление о том, что подлежащему присуще какое-либо предметное свойство. Например, Мэтэк тэт эньиэнольэл. «Я твоя мать».

Переходные глаголы в ремо-субъектной форме. Глаголы, обозначающие действие, предполагающее наличие объекта, в отношение которого оно было или может быть применено, являются переходными. Форма этого спряжения отвечает на вопросы типа Кин виэ? «Кто сделал?» Кин айи? «Кто стрелял?». Со смысловой стороны форма этого спряжения характеризуется тем, что логическое ударение концентрируется на подлежащем. Грамматически это выражается тем, что глагол не принимает ни личных окончаний, ни суффикса -мэ(p). Освобожденный от всех своих основных и важнейших грамматических средств выражения предикативности, глагол в этом случае выступает как бы в качестве побочного второстепенного признака подлежащего, которое выражается личным местоимением или именем существительным. Например: Мэт виэ «Я сделал». Мэт сусэй «Я бросил». Тэт виэ «Ты сделал». Другими словами, неоформленность переходного глагола показывает о логическом выделении подлежащего.

\section{Ремо-предикативная форма}

Со смысловой стороны ремо-предикативная форма характеризуется тем, что логическое ударение в предложении сосредотачивается на глаголе. Грамматически это выражается тем, что глагол оформляется префиксом - мэ(p) и личными окончаниями, имеющими три формы в зависимости от конечного звука основы спрягаемых глаголов.

\section{Непереходный глагол в ремо-предикативной форме}

\begin{abstract}
Мэт мэр ууйэн «Я ходил»
Тэт мэр ууйэк «Ты ходил»

Тудэл мэр ууй «Он ходил»

Muт мэр ууйэли «Мы ходил»

Tuт мэр ууйэмут «Вы ходили»

Титтэл мэр ууни «Они ходили».
\end{abstract}

Типы окончаний ремо-предикативной формы спряжения непереходных глаголов обусловлены конечными звуками корней и основ. После глагольных корней и основ, оканчивающихся на гласный, употребляются окончания: -йэн, -йэк, -й, -йэли, -йэмут, -ни. После отглагольных основ, оканчивающихся на -й и согласный, употребляются окончания: -чэн, -чэк, -4, -чэли, чэмут, -ни. После глагольных корней и основ, оканчивающихся звуками -н, -л, -дь (на согласные) и дифтонг -уо, употребляются: -дьэн, -дьэк, -ни (нь), -дьэли, -дьэмут, -ни.
Глаголы-лексические еАинишы, употребляюшиеся в роли «прилагательного» в ремо-предикативной форме

При помощи глаголов-лексических единиц, употребляющихся в роли «прилагательного» в ремо-предикативной форме, в предложении подлежащему присваивается какой-то новый качественный признак, либо устанавливается факт наличия данного признака, либо дается качественная оценка тех или иных поступков. Например:

1) Хомдамонолаалэлдақанэ, чирэмэдиэ Хабанинь мони: «Хадьир мэ чугумуйэк». Когда настала ранняя осень, птичка Плешивому сказала: «Ну, вот быстрым стал- ты";

2) Сэспэн маалагурқа кинлаамэдуок игэнул. Маархалльэ тороньэй, конмэгисчэ мэ ньаавэй. По обе стороны двери два щенка привязаны были. Один черный (был), другой белый (был).

Парадигма спряжения глаголов-лексических единиц, употребляющихся в роли «прилагательного» в ремо-предикативной форме:
Мэт мэ чамуодьэн. Ябольшой (был)
Тэт мэ чамуодьэк. Ты большой (был)
Тудэл мэ чамуонь. Он большой (был)
Мит мэ чамуодьэли. Мы большие (были)
Tит мэ чамуодьэмут. Вы большие (были)
Титтэл мэ чамуодьэни. Они большие (были)

Приведенные примеры показывают, что глаголы-лексические единицы, употребляющиеся в роли «прилагательного» в ремо-предикативной форме, имеют характер сказуемого, называющего и присваивающего данный признак его носителю. Анализируя парадигму спряжения глаголов-лексических единиц, употребляющиеся в роли «прилагательного» в ремо-предикативной форме, нетрудно установить, что ее показатели полностью совпадают со спряжением непереходных глаголов в этой форме:

1 форма: -йэн, -йэк, -й, -йэли, -йэмут, -ни;

2 форма: -чэн, -чэк, -4, -чэли, чэмут, -нu; 3) -дьэн, -дьэк, -ни (нь), -дьэли, -дьэмут, -дьэни.

\section{Атрибутивная форма лексических единич, употребляюшихся в роли «прилагательного»}

Атрибутивная форма лексических единиц, употребляющихся в роли «прилагательного» образуется при помощи суффиксов: 1) -й(э), 2) -чэ, 3) -дьэ. Например:

1) чамумуйэ мархиль «растущая девушка», йэнгурньэй куоскэ «пестрая кошка»;

2) амучэ чайлэ «хороший день»;

3) чайлэньдьэ нимэ «светлый дом». 


\section{Лексические еАинишы именного типа, употребляюшиеся в роли «прилагательного»}

Лексические единицы именного типа, употребляющиеся в роли «прилагательного» образуются при помощи суффиксов: 1)-хра,-ркэ; 2) -дьэ; 3) -йэ; 4) -йэ. Например:

1) пөмэркэ ньаачэ «округлое лицо»;

2) сугуриэльэлдьэ чиэмэлэ «прилипшая кровь»;

3) шанччдьаайэ көдэ «выпрашивающий человек»;

4) чэнчэ букварь «веселый букварь».

Особенность лексических единиц именного типа 2 и 3 групп, употребляющихся в роли «прилагательного» состоит в том, что в современном юкагирском языке при явлении субстантивации употребляются в роли существительных. Например, льитэгэдьиэйэ «кузнец», льитэгэндьэ «молот» и др.

Особенность лексических единиц, употребляющихся в роли прилагательного в тундренном диалекте юкагирского языка, т.е. «двоякость» их содержания и функционирования, свидетельствует о трудности выделения данной группы слов в отдельную часть речи.

Таким образом, субстантивация атрибутивных причастий, а также «оглаголивание» лексических единиц со значением "количества» и «качества», свидетельствуют о постоянном действующем процессе «оглаголивания» и субстантивации в современном юкагирском языке.

\section{ЛИТЕРАТУРА}

1. Иохельсон В.И. Одульский (юкагирский язык) // Языки и письменность народов Севера. - М.; Л., 1934. - Ч.3. Языки и письменность палеоазиатских народов. - С. 149-181.

2. Крейнович Е.А. Юкагирский язык. М.-Л.: Изд-во Академии наук СССР, 1958. - 288 С.

3. Крейнович Е.А. Юкагирский язык // Языки народов СССР. - Л.: Наука, 1968. - Т.5. - С. 435-454.

4. Крейнович Е.А. Исследования и материалы по юкагирскому языку. - Л.: Наука, 1982. - 302 с.

5. Курилов Г.Н. Юкагирско - русский словарь. Новосибирск: Наука, 2001. - 608 с.

6. Курилов Г.Н. Лексикология современного юкагирского языка. - Новосибирск: Наука, 2003. - 285 с.

7. Курилов Г.Н. Современный юкагирский язык: Учеб. пособие. Якутск: Офсет, 2006. - 280 с.

๑ Лукина Маргарита Петровна (margarita-lukina@yandex.ru ).

Журнал «Современная наука: актуальные проблемы теории и практики»

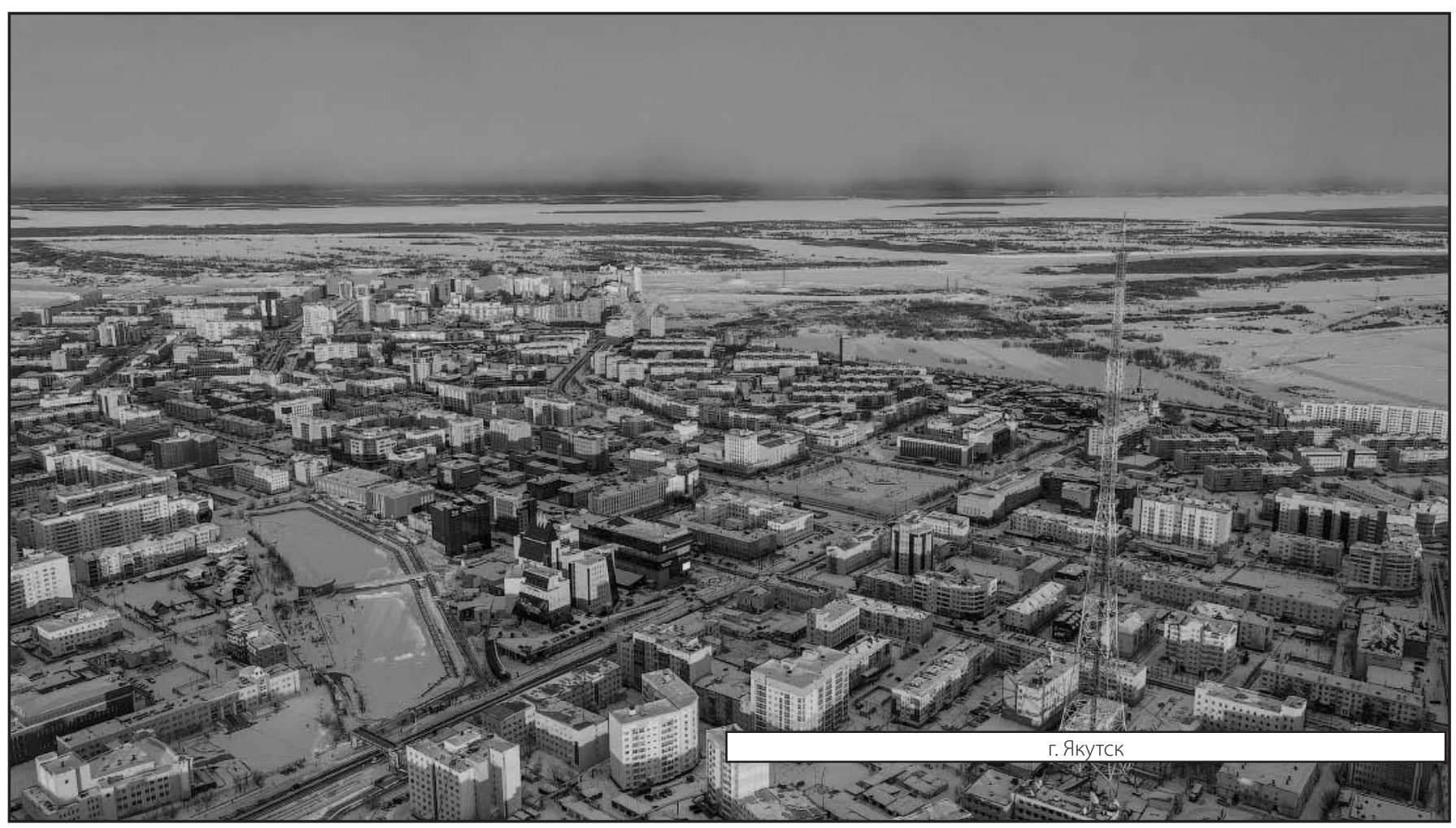

